Article

\title{
Iron-induced 3D nanoporous iron-cobalt oxyhydroxide on carbon cloth as a highly efficient electrode for oxygen evolution reaction
}

\author{
Guodong Chen a, , Jian Du b,t, Xilong Wang b, Xiaoyue Shi b, Zonghua Wang a,*, Han-Pu Liang b,c,\# \\ a College of Chemistry and Chemical Engineering, Shandong Sino-Japanese Center for Collaborative Research of Carbon Nanomaterials, \\ Qingdao University, Qingdao 266071, Shandong, China \\ b Qingdao Institute of Bioenergy and Bioprocess Technology, Chinese Academy of Sciences, Qingdao 266101, Shandong China \\ c Center of Materials Science and Optoelectronics Engineering, University of Chinese Academy of Sciences, Beijing 100049, China
}

\section{A R T I C L E I N F O}

\section{Article history:}

Received 22 May2019

Accepted 23 June 2019

Published 5 October 2019

\section{Keywords:}

3D nanoporous iron-cobalt

oxyhydroxide layer

Micro go chess piece arrays

Electrode material

Electro-oxidation

Oxygen evolution reaction

\begin{abstract}
A B S T R A C T
The development of highly efficient and cost-effective electrode materials for catalyzing the oxygen evolution reaction (OER) is crucial for water splitting technology. The increase in the number of active sites by tuning the morphology and structure and the enhancement of the reactivity of active sites by the incorporation of other components are the two main strategies for the enhancement of their catalytic performance. In this study, by combining these two strategies, a unique three-dimensional nanoporous Fe-Co oxyhydroxide layer coated on the carbon cloth (3D-FeCoOOH/CC) was successfully synthesized by in situ electro-oxidation methods, and directly used as a working electrode. The electrode, 3D-FeCoOOH/CC, was obtained by the Fe doping process in $\left(\mathrm{NH}_{4}\right)_{2} \mathrm{Fe}\left(\mathrm{SO}_{4}\right)_{2}$, followed by continuous in situ electro-oxidization in alkaline medium of "micro go chess piece" arrays on the carbon cloth (MCPAs/CC). Micro characterizations illustrated that the go pieces of MCPAs/CC were completely converted into a thin conformal coating on the carbon cloth fibers. The electrochemical test results showed that the as-synthesized 3D-FeCoOOH/CC exhibited enhanced activity for OER with a low overpotential of $259 \mathrm{mV}$, at a current density of $10 \mathrm{~mA} \mathrm{~cm}{ }^{-2}$, and a small Tafel slope of $34.9 \mathrm{mV} \mathrm{dec}^{-1}$, as well as superior stability in $1.0 \mathrm{~mol} \mathrm{~L}^{-1} \mathrm{KOH}$ solution. The extensive analysis revealed that the improved electrochemical surface area, conductivity, Fe-Co bimetallic composition, and the unique 3D porous structure together contributed to the enhanced OER activity of 3D-FeCoOOH/CC. Furthermore, the synthetic strategy applied in this study could be extended to fabricate a series of Co-based electrode materials with the dopant of other transition elements.
\end{abstract}

(C) 2019, Dalian Institute of Chemical Physics, Chinese Academy of Sciences. Published by Elsevier B.V. All rights reserved.

\section{Introduction}

The rapidly increasing demand for sustainable and renewa- ble clean energy sources has attracted considerable interest in promoting the development of energy storage and conversion technologies with low cost, high efficiency and environmental

\footnotetext{
* Corresponding author. E-mail: wangzonghua@qdu.edu.cn

\# Corresponding author. E-mail: lianghp@qibebt.ac.cn

† These authors contributed equally to this work.

This work was supported by the Taishan Scholar Program of Shandong (ts201511027), and the Natural Science Foundation of Shandong Province (2018GGX102030). Han-Pu Liang is thankful for support from the "Hundred Talent Program" of Chinese academy of Sciences (CAS) (RENZI[2015] 70HAO, Y5100619AM), DICP and QIBEBT (UN201804), Dalian National Laboratory For Clean Energy (DNL), CAS, and Research Innovation Fund (QIBEBT SZ201801).

DOI: S1872-2067(19)63401-7 | http://www.sciencedirect.com/science/journal/18722067 | Chin. J. Catal., Vol. 40, No. 10, October 2019
} 
benignity [1,2]. Electrochemical water splitting, an efficient and environmentally friendly technology for producing hydrogen fuel and oxygen, is a promising pathway to convert electrical energy into chemical energy. However, the electrolytic efficiency is limited by the oxygen evolution reaction (OER) $[3,4]$. To date, $\mathrm{IrO}_{2}$ and $\mathrm{RuO}_{2}$ are known as the most active OER catalysts; however, some limitations exist such as high cost and relatively poor stability in alkaline medium. Therefore, it is desirable to explore inexpensive, highly efficient and stable OER catalysts based on earth-abundant elements [5-7].

Over the past decades, earth-abundant transition metal catalysts, particularly Co-based catalysts, including metal oxides $[8,9]$, oxyhydroxides $[10,11]$, nitrides $[6,12]$, phosphides $[13,14]$, sulfides [15], selenides [16] and perovskite solids [17] , have been extensively synthesized and applied in water splitting. However, well-studied cobalt oxides or (oxy) hydroxides usually suffer from low conductivity and reactivity, in comparison to the corresponding multimetal electrocatalysts doped with other metal such as Fe and Ni $[4,11]$, which results in large overpotentials required to reach the desired current density of $10 \mathrm{~mA} \mathrm{~cm}^{-2}$ during the OER process [5,13]. Therefore, significant efforts have been directed toward improving their catalytic performance $[18,19]$. Increasing the number and reactivity of active sites are the two main strategies for enhancing their catalytic performance. The first could be achieved by tuning the morphology and structure, such as nanosheet arrays [4,20], ultrathin characteristics [21,22] and porous structure [23-25], to enhance their OER performance. For example, a porous structure is one of the most important requirements because it facilitates the increase in specific surface area, buffering of volume change, and gas release [26,27]. Jiao et al. [9] synthesized ordered mesoporous cobalt oxide as a highly efficient oxygen evolution catalyst. The second is the incorporation of other components to optimize the electronic structure, thereby increasing the reactivity of the catalysts [5]. Over the last few years, it has been reported that the incorporation of Fe could significantly increase the performance of Co-based catalysts. Han et al. [19] synthesized nanosized porous $\mathrm{Fe}-\mathrm{CoOOH}$ via etching the CoFeAl-LDH/G in an alkali solution to enhance the activity of Co-based catalysts. These nanosized Fe-CoOOH/G are ultrasensitive and highly effective for OER. Li et al. [23] prepared activating $\mathrm{CoOOH}$ porous nanosheet arrays by partial Fe substitution for efficient oxygen evolution reaction. Thus, the development of novel catalysts combing these two strategies for OER is of importance.

Herein, we have successfully synthesized 3D porous FeCo oxyhydroxide layer coated on the carbon cloth (3D-FeCoOOH/CC) as a highly efficient electrode with a facile and cost-effective electro-oxidation method. The Fe components and unique 3D porous structures were successfully introduced and created after Fe doping and in situ electro-oxidation process, which favored the exposure of more active sites, thereby accelerating the diffusion of electrolytes and electronic transfer, as well as effectively buffering the volume change for oxygen release. The electrochemical testing results showed that the as-synthesized 3D-FeCoOOH/CC exhibited a superior OER activity with a relatively low overpotential of $259 \mathrm{mV}$ at $10 \mathrm{~mA} \mathrm{~cm}{ }^{-2}$, with a small Tafel slope of $34.9 \mathrm{mV}$ $\mathrm{dec}^{-1}$, and excellent stability in $1.0 \mathrm{~mol} \mathrm{~L}^{-1} \mathrm{KOH}$ solution, thereby outperforming commercial $\mathrm{IrO}_{2}$ catalysts.

\section{Experimental}

\subsection{Chemicals}

Carbon cloth (CC) was purchased from Shanghai Hesen Electric Co., Ltd. Cobalt nitrate hexahydrate $\left(\mathrm{Co}\left(\mathrm{NO}_{3}\right)_{2} \cdot 6 \mathrm{H}_{2} \mathrm{O}\right)$, hydrochloric acid $(\mathrm{HCl})$, and ethanol were purchased from Aladdin Chemistry Co. Ammonium fluoride $\left(\mathrm{NH}_{4} \mathrm{~F}\right)$, urea, ammonium iron(II) sulfate $\left(\left(\mathrm{NH}_{4}\right)_{2} \mathrm{Fe}\left(\mathrm{SO}_{4}\right)_{2}\right)$, and potassium hydroxide $(\mathrm{KOH})$ were purchased from Sinopharm Chemical Reagent Co., Ltd. Nafion (5 wt.\%) was purchased from Dupont Co. Iridium oxide $\left(\mathrm{IrO}_{2}\right)$ was purchased from Makclin Chemistry Co. All chemicals were used as received without any further purification. Distilled water was obtained through the Millipore system.

\subsection{Synthesis}

\subsubsection{Synthesis of "micro go chess piece" arrays on carbon cloth (MCPAs/CC)}

Typically, MCPAs/CC is prepared by a modified hydrothermal reaction [28]. A piece of $\mathrm{CC}(2 \mathrm{~cm} \times 4 \mathrm{~cm})$ was sonicated in $\mathrm{HCl}$, acetone and deionized water sequentially for $30 \mathrm{~min}$ to ensure that the surface of $\mathrm{CC}$ was clean. $\mathrm{Co}\left(\mathrm{NO}_{3}\right)_{2} \cdot 6 \mathrm{H}_{2} \mathrm{O}(2.5$ mmol), $\mathrm{NH}_{4} \mathrm{~F}(2.5 \mathrm{mmol})$, and urea $(12.5 \mathrm{mmol})$ were dissolved in a mixture of $40 \mathrm{~mL}$ ethylene glycol and $5 \mathrm{~mL}$ deionized water under vigorous stirring for $30 \mathrm{~min}$ to obtain a uniform solution. Subsequently, the uniform solution and a piece of clean CC were transferred into a $100 \mathrm{~mL}$ Teflon-lined stainless-steel autoclave and heated at $120^{\circ} \mathrm{C}$ for $6 \mathrm{~h}$. After the autoclave naturally cooled down to room temperature, the MCPAs/CC was retrieved, washed with ethanol repeatedly, and dried at $60{ }^{\circ} \mathrm{C}$ for $4 \mathrm{~h}$.

\subsubsection{Synthesis of $3 \mathrm{D}-\mathrm{FeCOOOH} / \mathrm{CC}$}

The 3D-FeCoOOH/CC was fabricated via two steps. First, the Fe doping process was carried out via the in situ electro-oxidization of MCPAs/CC in $0.01 \mathrm{~mol} \mathrm{~L}^{-1}\left(\mathrm{NH}_{4}\right)_{2} \mathrm{Fe}\left(\mathrm{SO}_{4}\right)_{2}$ at a current density of $1.2 \mathrm{~mA} \mathrm{~cm}-2$ for a specific time period. To obtain the optimum catalytic activity, the dopant process time was set at 15, 30 and $45 \mathrm{~min}$. Subsequently, the precursors were cleaned repeatedly using distilled water to remove the excess $\mathrm{Fe}$, followed by direct use as the working electrode in $1.0 \mathrm{~mol} \mathrm{~L}^{-1} \mathrm{KOH}$ at an anodic current density of $10.0 \mathrm{~mA} \mathrm{~cm}^{-2}$ for $10 \mathrm{~h}$ to obtain 3D-FeCoOOH/CC. Unless specifically noted, the 3D-FeCoOOH/CC mentioned later in this article refers to the sample with an Fe doping time of $30 \mathrm{~min}$.

\subsubsection{Synthesis of 3D micro go chess piece like cobalt} oxyhydroxide on carbon cloth $(3 \mathrm{D}-\mathrm{CoOOH} / \mathrm{CC})$

For comparison, the 3D-CoOOH/CC was fabricated using the above-mentioned method with the absence of the Fe doping process. 


\subsubsection{Preparation of $\mathrm{IrO}_{2}$ electrode}

A suspension was prepared by dispersing $\mathrm{IrO}_{2}$ powders $(5$ $\mathrm{mg}$ ) in a mixture of $0.99 \mathrm{~mL}$ ethanol and $0.01 \mathrm{~mL} 5 \mathrm{wt} . \%$ Nafion solution. The mixed solution was sonicated for $20 \mathrm{~min}$ to obtain a homogeneous catalyst ink. The dispersion $(0.2 \mathrm{~mL})$ was transferred onto a piece of CC $(1 \mathrm{~cm} \times 2 \mathrm{~cm})$ using a pipette. The mass loading was controlled at $1.0 \mathrm{mg} \mathrm{cm}^{-2}$.

\subsection{Material characterization}

The catalyst loading was measured as $1.25 \mathrm{mg} \mathrm{cm}^{-2}$ by the traditional gravimetric method. The morphology and structures were analyzed using field emission scanning electron microscopy (SEM; Hitachi S-4800F) and high-resolution transmission electron microscopy (HRTEM; FEI Tencnai G2F30). The powder X-ray diffraction (XRD) patterns were collected on a Bruker D8AVANCE X-ray powder diffraction spectrometer. Nitrogen adsorption-desorption isotherms were measured using a Micromeritics ASAP 2000 system. The valency of the different components of the catalysts was evaluated by X-ray photoelectron spectroscopy (XPS; VG-Multi-lab 2000).

\subsection{Electrochemical measurements}

All electrochemical measurements were carried out in a standard three-electrode system with a CHI 660E electrochemical analyzer (CH Instruments, Inc., Shanghai) using $1.0 \mathrm{~mol} \mathrm{~L}^{-1}$ $\mathrm{KOH}$ as the electrolyte. The synthesized 3D-FeCoOOH/CC was used as the working electrode, a graphite plate as the counter electrode, and $\mathrm{Hg} / \mathrm{HgO}$ electrode as the reference electrode. The potentials reported in this study were calibrated to the reversible hydrogen electrode (RHE), using the following equation:

$$
E_{\mathrm{RHE}}=E_{\mathrm{Hg} / \mathrm{HgO}}+0.098+0.0591 \mathrm{pH}
$$

The electrochemically active surface area (ECSA) was estimated from the electrochemical double-layer capacitance based on a published report [29]. The electrochemical capacitance $\left(C_{\mathrm{dl}}\right)$ was estimated by cyclic voltammograms measured in a non-Faradaic region from $1.18 \mathrm{~V}$ to $1.26 \mathrm{~V}$ at various scan rates of $5-25 \mathrm{mV} \mathrm{s}^{-1}$. The ECSA was calculated according to Equation (2) below:

$$
\mathrm{ECSA}=C_{\mathrm{dl}} / C_{\mathrm{s}}
$$

The general specific capacitance for the metal oxides or oxyhydroxides, $C_{\mathrm{s}}=0.040 \mathrm{mF} \mathrm{cm}{ }^{-2}$ in $1.0 \mathrm{~mol} \mathrm{~L}^{-1} \mathrm{KOH}$ was employed based on previous reports [29].

\section{Results and discussion}

\subsection{Physical characterizations}

The overall synthetic strategy for 3D-FeCoOOH/CC is illustrated in Fig. 1. First, MCPAs/CC was synthesized by a simple hydrothermal reaction and directly used as a working electrode. Second, Fe doping process was carried out via the in situ anodic oxidization of MCPAs/CC in $0.01 \mathrm{~mol} \mathrm{~L}^{-1}\left(\mathrm{NH}_{4}\right)_{2} \mathrm{Fe}\left(\mathrm{SO}_{4}\right)_{2}$ for a fixed period of time, at $1.2 \mathrm{~mA} \mathrm{~cm}^{-2}$. The electrode was in situ electro-oxidized in $1.0 \mathrm{~mol} \mathrm{~L}^{-1} \mathrm{KOH}$ solution at $10 \mathrm{~mA} \mathrm{~cm}-2$

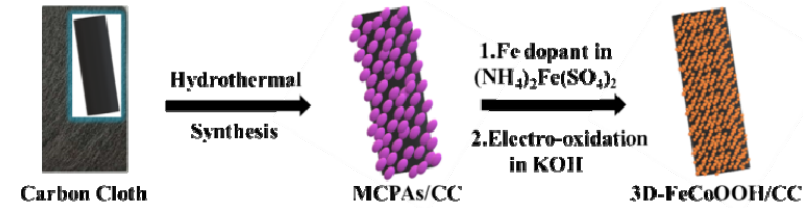

Fig. 1. Schematic of the synthesis of 3D-FeCoOOH/CC.

for $10 \mathrm{~h}$ continuously, to afford 3D-FeCoOOH/CC. To obtain the optimum catalytic activity, the Fe doping process was fixed at different periods and the corresponding catalytic activity is shown in Fig. S1. It is evident that the 3D-FeCoOOH/CC with an Fe doping time $30 \mathrm{~min}$ in $\left(\mathrm{NH}_{4}\right)_{2} \mathrm{Fe}\left(\mathrm{SO}_{4}\right)_{2}$ possesses the best OER catalytic activity. As 3D-FeCoOOH/CC exhibited the best activity, in-depth characterizations were performed on it.

The morphologies of MCPAs/CC and 3D-FeCoOOH/CC were investigated using SEM. Fig. 2a shows the low-magnification SEM image of MCPAs/CC. It is clearly observed that numerous micro go pieces $(\sim 1.3 \mu \mathrm{m})$ are coated on the carbon fiber. The high-magnification SEM images in Figs. $2 \mathrm{~b}$ and 2c show that every micro go piece is composed of a large number of uniformly intertwined nanorods. The corresponding energy-dispersive X-ray spectroscopy (EDS) spectrum in Fig. S2 demonstrates that it contains $\mathrm{C}, \mathrm{O}, \mathrm{F}$ and Co. For 3D-FeCoOOH/CC, the low- and high-magnification SEM images in Figs. $2 \mathrm{~d}$ and $2 \mathrm{e}$ show that the carbon fiber is coated with a uniform layer, which comprises of numerous small nanoparticles $(\sim 10 \mathrm{~nm})$. The corresponding EDS spectrum in Fig. S3 shows the presence of $\mathrm{C}, \mathrm{O}, \mathrm{Fe}$ and Co elements (Fe:Co molar ratio of 0.034:1), indicating the dopant of Fe element and the complete removal of F. Besides, the SEM images and the corresponding EDS spectra of 3D-FeCoOOH/CC with the Fe dopant times of 15 and 45 min are shown in Figs. S4-S7. The SEM results demonstrate that $3 \mathrm{D}-\mathrm{FeCoOOH} / \mathrm{CC}$ has a unique 3D porous structure, and that the doped Fe atoms play a key role in

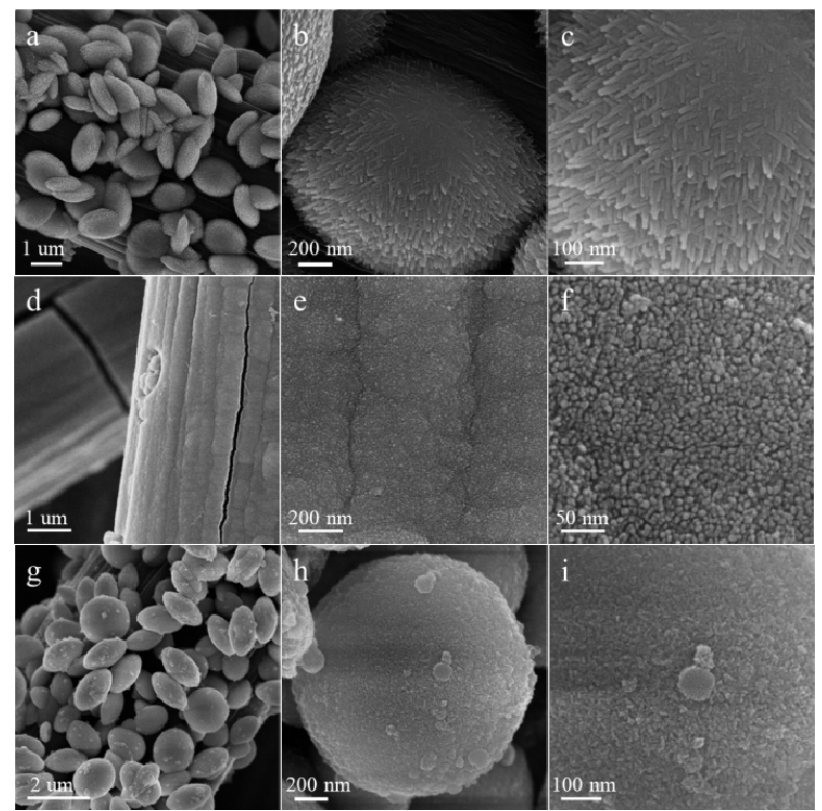

Fig. 2. SEM images of MCPAs/CC (a-c), 3D-FeCoOOH/CC (d-f), and $3 \mathrm{D}-\mathrm{CoOOH} / \mathrm{CC}(\mathrm{g}-\mathrm{i})$ at various magnifications. 
tailoring and converting MCPAs/CC into 3D-FeCoOOH/CC [19]. Electrochemical tests indicate that the 3D-FeCoOOH/CC obtained with an Fe doping time of 30 min exhibits the best catalytic activity, indicating a suitable Fe:Co ratio for OER. For comparison, 3D-CoOOH/CC was synthesized exclusively by the electro-oxidation in $1.0 \mathrm{~mol} \mathrm{~L}-1 \mathrm{KOH}$ without the $\mathrm{Fe}$ doping process. The low-magnification SEM image in Fig. 2g shows that 3D-CoOOH/CC still exhibits a micro go piece morphology without obvious changes, whereas the high-magnification SEM images in Figs. $2 \mathrm{~h}$ and $2 \mathrm{i}$ demonstrate that the nanorods are completely transformed into small nanoparticles $(\sim 10 \mathrm{~nm})$, similar to the morphology of 3D-FeCoOOH/CC.

The nanostructure of the 3D-FeCoOOH layer scraped from carbon fiber was investigated by transmission electron microscopy (TEM). As shown in Fig. 3a, the 3D-FeCoOOH layer has a porous structure. HRTEM and selected area electron diffraction (SAED) analyses were performed to further study the morphology and crystallographic properties. The HRTEM image in Fig. $3 \mathrm{~b}$ and the inset corresponding to the SAED pattern both indicate that 3D-FeCoOOH/CC exhibits a polycrystalline structure. The first, third and fourth diffraction rings close to the central diffraction spot in the SAED pattern correspond to the crystallographic planes of $\mathrm{CoOOH}$ (110), $\mathrm{CoOOH}$ (021) and CoOOH (140), respectively. Meanwhile, the second diffraction ring corresponds to the crystallographic plane of FeOOH (310), suggesting that $\mathrm{FeOOH}$ and a main $\mathrm{CoOOH}$ phase exist. High angle annular dark field scanning TEM (HADDF-STEM) images and the corresponding elemental mappings shown in Figs. 3c- $\mathrm{f}$ indicate that Co (red), $\mathrm{O}$ (blue) and Fe (yellow) are distributed uniformly. The formation of a porous structure was further defined using Brunauer-Emmett-Teller (BET) gas sorptometry measurements, and the corresponding results are shown in Fig. S8. The shapes of the hysteresis loops of 3D-CoOOH/CC and 3D-FeCoOOH/CC were both identified as type $\mathrm{H} 3$ according to the International Union of Pure and Applied Chemistry (IUPAC) classification [4], indicating the formation of porous structures.

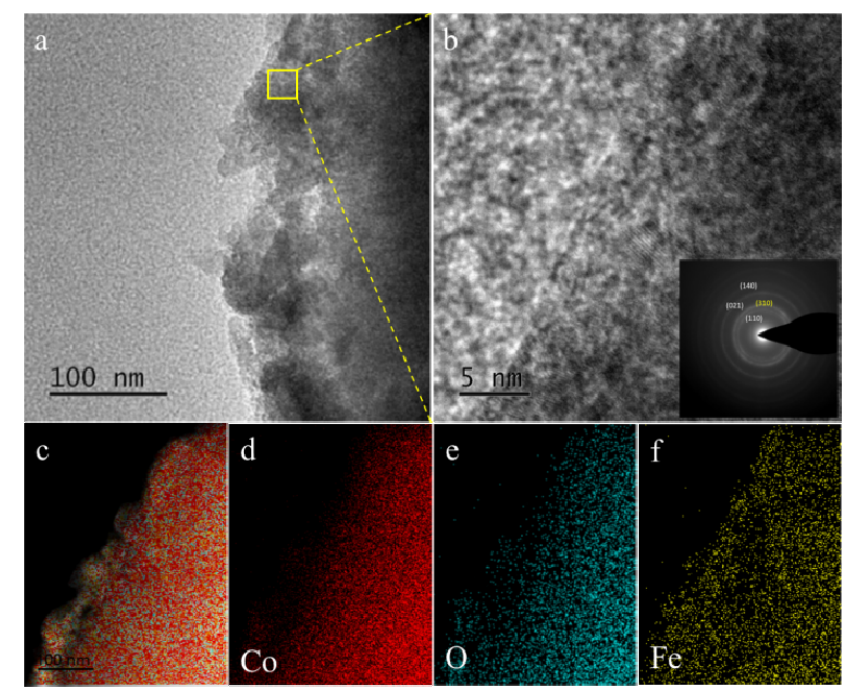

Fig. 3. (a) TEM image and (b) HRTEM image of 3D-FeCoOOH layer (inset: SAED pattern of 3D-FeCoOOH/CC); (c) Overlay of the HADDF-STEM image and elemental mappings; (d-f) elemental mappings of $\mathrm{Co}, \mathrm{O}$, and $\mathrm{Fe}$ of the 3D-FeCoOOH layer, respectively.
This result was consistent with the SEM data. Additionally, according to the BET analysis, the total specific surface areas of MCPAs/CC and 3D-CoOOH/CC are $23.59 \mathrm{~m}^{2} \mathrm{~g}^{-1}$ and $25.80 \mathrm{~m}^{2}$ $\mathrm{g}^{-1}$, respectively. When Fe was introduced into 3D-CoOOH/CC, the specific surface area of 3D-FeCoOOH/CC further increased to $27.24 \mathrm{~m}^{2} \mathrm{~g}^{-1}$, which was facilitated the exposure of more active sites.

The XRD patterns of the as-synthesized electrodes and CC are shown in Fig. S9. Fig. S9a shows two obvious diffraction peaks for $3 \mathrm{D}-\mathrm{FeCoOOH} / \mathrm{CC}$ at $26.4^{\circ}$ and $54.5^{\circ}$, which could be attributed to the (002) and (004) planes of CC. From the magnification in Fig. S9b, notably, no obvious diffraction peak for 3D-FeCoOOH/CC was observed. Fourier transform infrared spectroscopy (FT-IR) analysis was further performed to explore the chemical composition of 3D-FeCoOOH/CC. It can be concluded from Fig. S10 that MCPAs/CC is most likely composed of fluorinated ethylene glycol alkoxide, and that the obtained products after the two-step electrochemical oxidation process are mainly metal oxyhydroxides [35].

High-resolution XPS was carried out to determine the valency of different components. The XPS survey of MCPAs/CC presented in Fig. S11 shows the presence of C, O, F and Co elements, while 3D-FeCoOOH/CC shows the presence of $\mathrm{C}, \mathrm{O}, \mathrm{Fe}$ and Co elements. The Co $2 p$ high-resolution XPS spectrum of MCPAs/CC is shown in Fig. S12. The binding energies of Co $2 p_{1 / 2}$ and Co $2 p_{3 / 2}$ are located at 807.8 and $791.9 \mathrm{eV}$, respectively, revealing the $\mathrm{Co}^{2+}$ oxidation state. Fig. $4 \mathrm{a}$ shows the comparison of the Co $2 p$ high-resolution XPS spectra for 3D-CoOOH/CC and 3D-FeCoOOH/CC. For 3D-CoOOH/CC, the two peaks with binding energies of 780.5 and $795.7 \mathrm{eV}$ correspond to the typical Co $2 p_{3 / 2}$ and Co $2 p_{1 / 2}$ orbitals, while for 3D-FeCoOOH/CC, these could be attributed to 780.9 and 796.1 $\mathrm{eV}$. This result indicates that Co is present in the trivalent oxidation state [19,32]. As expected, the high-resolution Co $2 p$ spectra of 3D-FeCoOOH/CC exhibits a $0.4 \mathrm{eV}$ shift to a higher binding energy compared with the trend exhibited for 3D-CoOOH/CC, indicating a modulated electronic structure of the Co atoms and a strong electronic interaction between Co and Fe atoms [19]. Moreover, the enhanced Co satellite peak of 3D-FeCoOOH/CC at $\sim 785 \mathrm{eV}$ indicates the rearrangements of Co $3 d$ electron population owing to the degeneracy breaking of Co ions, which is consistent with the reports in the literature [36]. Additionally, the rearrangements of the Co $3 d$ electron population caused an increase in the electron density of the Co atoms, which facilitated the enhancement of catalytic activity [23,37]. Fig. 4b shows the high-resolution XPS spectrum for Fe $2 p$ of 3D-FeCoOOH/CC. The spectrum displays two major peaks at binding energies of $725.0 \mathrm{eV}$ and $712.5 \mathrm{eV}$, revealing the characteristics of $\mathrm{Fe}^{3+}[19,31]$. Furthermore, it has been reported that the adsorption energy of $\mathrm{OH}$ is considerably strong for $\mathrm{FeOOH}$, whereas it is too weak on $\mathrm{CoOOH}$ [5]. The incorporation of Fe could modulate the adsorption energy of $\mathrm{OH}$ on the catalysts. As shown in Fig. S13, the high-resolution $01 s$ spectrum can be clearly defined into four characteristic peaks of oxygen atoms (01-04) at binding energies of 530.2, 531.5, 532.2 and $533.0 \mathrm{eV}$, corresponding to a typical 0 from $\mathrm{O}^{2-}(01)$, $\mathrm{O}$ from the $\mathrm{OH}^{-}(\mathrm{O} 2)$, hydroxyl groups or surface-adsorbed 

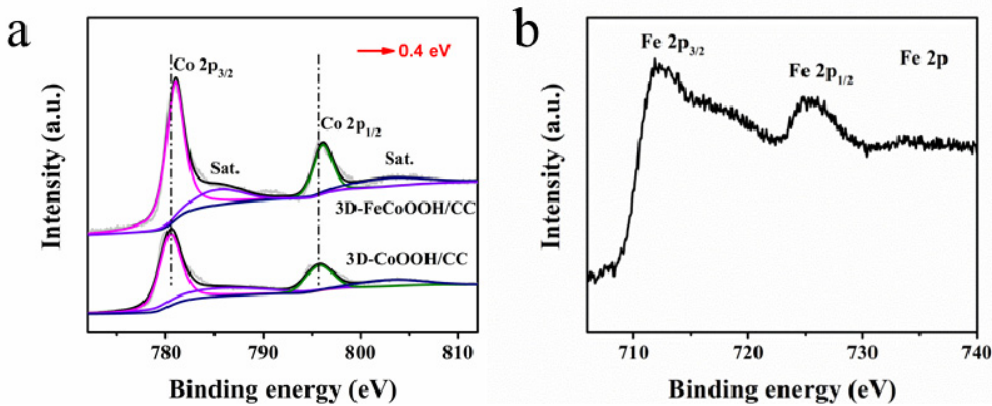

Fig. 4. (a) Co $2 p$ high-resolution XPS spectra of 3D-CoOOH/CC and 3D-FeCoOOH/CC; (b) Fe $2 p$ high-resolution XPS spectrum of 3D-FeCoOOH/CC.

oxygen (03) and surface-adsorbed water molecules (04), respectively $[18,33,34]$. Based on the analyses of FT-IR and XPS results, it can be concluded that the formed product should be Fe-Co oxyhydroxide.

\subsection{Evaluation of the OER electrocatalytic activity}

The electrochemical properties of the as-synthesized catalysts were evaluated in a standard three-electrode system using $1.0 \mathrm{~mol} \mathrm{~L}^{-1} \mathrm{KOH}$ as the electrolyte. According to the linear sweep voltammetry (LSV) curves in Fig. 5a, 3D-FeCoOOH/CC exhibits the best catalytic activity for OER. The obtained 3D-FeCoOOH/CC shows an onset potential (1.4 V) smaller than those of $3 \mathrm{D}-\mathrm{CoOOH} / \mathrm{CC}$ and $\mathrm{IrO}_{2}$. The potential required to reach a current density of $10 \mathrm{~mA} \mathrm{~cm}^{-2}$ and the current density at an overpotential of $300 \mathrm{mV}$ has been widely investigated to evaluate the catalytic activity for OER [38,39]. It can be seen from Fig. $5 b$ (black columns) that to drive the current density of $10 \mathrm{~mA} \mathrm{~cm}^{-2}$, 3D-FeCoOOH/CC requires a minimum overpotential of $259 \mathrm{mV}$. As illustrated in Fig. 5b (red columns), 3D-FeCoOOH/C exhibits a current density of $137 \mathrm{~mA} \mathrm{~cm}{ }^{-2}$, which is much larger than those of $3 \mathrm{D}-\mathrm{CoOOH}$ and $\mathrm{IrO}_{2}$. It can be concluded that 3D-FeCoOOH/C exhibits an outstanding OER performance in comparison to the performance for others. Additionally, 3D-FeCoOOH/CC exhibits the highest mass electrocatalytic activity for OER (Fig. S14).

The OER reaction kinetics of $\mathrm{FeCoOOH} / \mathrm{CC}$ was investigated by the Tafel slope according to the Tafel equation $(\eta=\operatorname{blog} j+a$, where $a, b$, and $j$ are a constant, the Tafel slope, and the current density, respectively) [25,29]. As shown in Fig. 5c, the Tafel

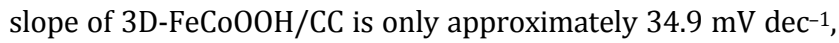
which is lower than those of 3D-CoOOH/CC (59.2 mV dec $\left.{ }^{-1}\right)$ and $\mathrm{IrO}_{2}\left(80.0 \mathrm{mV} \mathrm{dec}^{-1}\right)$, indicating the most favorable OER kinetics [39]. To compare the catalytic activity of 3DFeCoOOH/CC with those for the reported Co-based electrocatalysts and other state-of-the-art electrocatalysts, the overpotential at $10 \mathrm{~mA} \mathrm{~cm}^{-2}$ and the corresponding Tafel slope are listed in Table S3. It is clearly observed that the as-synthesized 3D-FeCoOOH/CC exhibits superior catalytic activity compared to those of the reported electrocatalysts.

In addition to the catalytic activity, stability is of importance as it is required for commercial applications [2]. The multi-current step chronopotentiometric curve of 3D-FeCoOOH/CC in Fig. $5 \mathrm{~d}$ shows that the potential rapidly stabilizes at $1.53 \mathrm{~V}$ and remains steady for $20 \mathrm{~min}$. An analogous response is observed through the consequent chronopotentiometric processes, which reflects the superior mass transportation property of the 3D-FeCoOOH/CC electrode $[20,40]$. The long-term stability was further evaluated by chronopotentiometric method at 20 $\mathrm{mA} \mathrm{cm}-2$, and the corresponding curves are shown in Fig. 5e. It is determined that the overpotential of 3D-FeCoOOH/CC shows almost no change after $100 \mathrm{~h}$ of testing, while $\mathrm{IrO}_{2}$ shows noticeable degradations only after $20 \mathrm{~h}$ of testing, indicating the superior stability of 3D-FeCoOOH/CC compared to that of $\mathrm{IrO}_{2}$. After $100 \mathrm{~h}$ of testing, the SEM images in Fig. S15 show that the 3D-FeCoOOH/CC retains its porous structure without noticeable changes. This indicates that $3 \mathrm{D}-\mathrm{FeCoOOH} / \mathrm{CC}$ is structurally robust and highly stable, which is favorable for practical application.

To investigate the reasons for the high catalytic activity of 3D-FeCoOOH/CC, the electrochemically active surface area (ECSA) was measured by the double-layer capacitance $\left(C_{\mathrm{dl}}\right)$ method in $1.0 \mathrm{~mol} \mathrm{~L}^{-1} \mathrm{KOH}$ solution in no-Faradaic current potential range (1.18-1.26 V) [21]. As shown in Figs. S16a and S16b, the current density of 3D-FeCoOOH/CC at $1.22 \mathrm{~V}$ is nearly five times that of 3D-CoOOH/CC. The different assembly of these nanoparticles could be the key to this enhancement. They are a part of a thin conformal coating in 3D-CoOOH/CC in contrast to the micro go shape in 3D-CoOOH/CC, where the center of the go pieces might be not accessible. The $C_{\mathrm{dl}}$ values of 3D-FeCoOOH/CC and 3D-CoOOH/CC shown in Fig. S16c are 88.5 and $16.3 \mathrm{mF} \mathrm{cm}^{-2}$, and the corresponding ECSA values are 2212.5 and $407.5 \mathrm{~cm}^{2}$, respectively, indicating more exposed active sites. The higher ECSA of 3D-FeCoOOH/CC further confirms the compositional and structural advantages in terms of the exposure of catalytic active sites [41].

The electrochemical impedance spectroscopy (EIS) and the corresponding circuit model fitting analysis were further performed (Fig. S16d) at an overpotential of $300 \mathrm{mV}$. The equivalent circuit of EIS is comprised of a solution resistance $\left(R_{\mathrm{S}}\right)$, charge-transfer resistance $\left(R_{\mathrm{ct}}\right)$, and constant phase element (CPE) [23]. The $R_{\mathrm{ct}}$ of $3 \mathrm{D}-\mathrm{FeCoOOH} / \mathrm{CC}$ is $0.797 \Omega$, which is lower than that of 3D-CoOOH/CC (5.636 $\Omega$ ), indicating a faster electron transfer in 3D-FeCoOOH/CC. The high conductivity of 3D-FeCoOOH/CC plays a key role in enhancing its OER performance, particularly at low overpotentials [11].

The above experimental results demonstrate that 3D-FeCoOOH/CC exhibits excellent electrocatalytic perfor- 
a

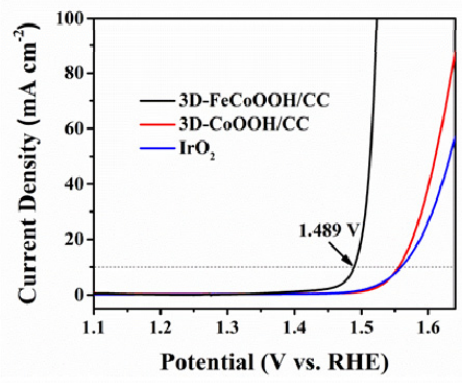

C

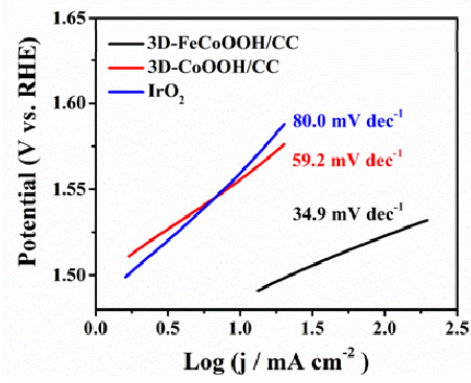

b

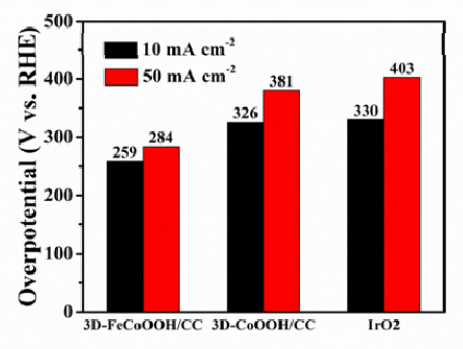

d

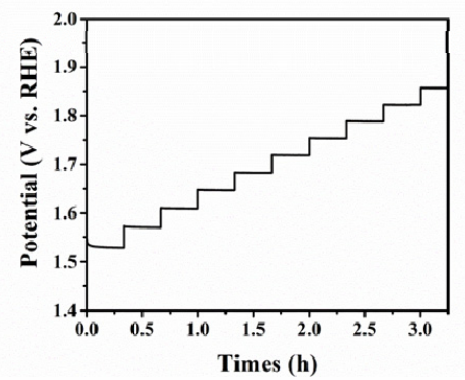

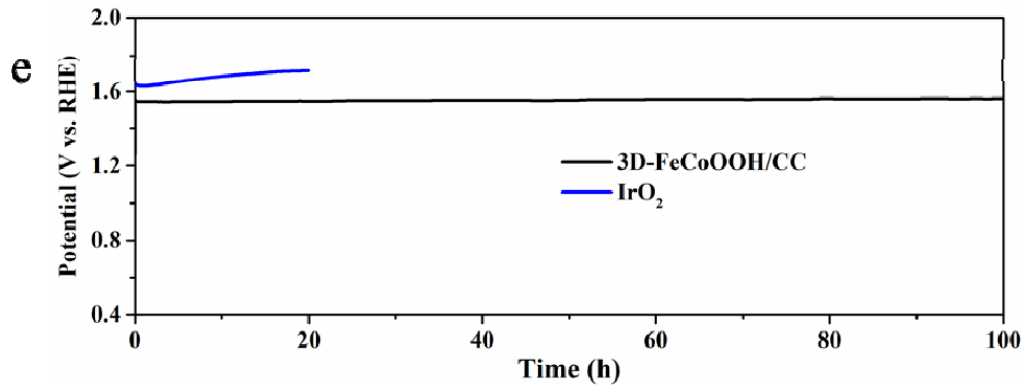

Fig. 5. (a) LSV curves and (c) Tafel plots of 3D-FeCoOOH/CC, 3D-CoOOH/CC, and $\mathrm{IrO}_{2}$ with IR-correction; (b) Comparison of the overpotentials at a current density of $10 \mathrm{~mA} \mathrm{~cm}-2$ and the current density at an overpotential of $300 \mathrm{mV}$ for 3D-FeCoOOH/CC, 3D-CoOOH/CC, and IrO 2 , respectively; (d) Chronopotentiometric responses for 3D-FeCoOOH/CC at various current densities (20-200 mA $\mathrm{cm}^{-2}$ with an increment of $20 \mathrm{~mA} \mathrm{~cm}^{-2}$ ); (e) Chronopotentiometry curves of 3D-FeCoOOH/CC and $\mathrm{IrO}_{2}$ at a constant current density of $20 \mathrm{~mA} \mathrm{~cm}^{-2}$.

mances for OER. This could be attributed to the following features. First, the increased ECSA, conductivity and mass transportation caused by the incorporation of Fe led to its enhanced OER performance. Second, the strong interaction between Co and doped Fe modulated the electron density and the adsorption energies of $\mathrm{OH}$ on the catalysts, leading to the enhanced OER performance. Third, the unique 3D porous structure of 3D-FeCoOOH/CC possessed large surface area and it favored the exposure of more active sites, increase in the contact area of electrolyte and catalyst, and release of generated oxygen. Fourth, the unique 3D porous structure was highly robust and stable, leading to a good long-term stability. Owing to these unique features, the as-synthesized 3D-FeCoOOH/CC electrode exhibited superior electrocatalytic performances for OER.

\section{Conclusions}

In summary, we have successfully developed an efficient strategy for the assembly of 3D-FeCoOOH/CC. The 3D-FeCoOOH/CC possessed a low overpotential of $259 \mathrm{mV}$ at $10 \mathrm{~mA} \mathrm{~cm}-2$ and small Tafel slope of $34.9 \mathrm{mV} \mathrm{dec}^{-1}$ for OER, thereby outperforming Ir- and Ru-based catalysts. The as-synthesized 3D-FeCoOOH/CC also exhibited excellent stabil- ities after continuous electrolysis in alkaline electrolyte for more than $100 \mathrm{~h}$ with negligible activity decay. The 3D-FeCoOOH/CC with excellent OER catalytic activity has excellent potential for application in water splitting. Furthermore, the synthetic strategy is also of significance for the fabrication of a series of Co-based electrode materials with the dopant of other earth-abundant transition elements.

\section{Acknowledgments}

This work was supported by the National Natural Science Foundation of China (21475071), the Taishan Scholar Program of Shandong (ts201511027), and the Natural Science Foundation of Shandong Province (2018GGX102030). Han-Pu Liang is thankful for support from the "Hundred Talent Program" of Chinese academy of Sciences (CAS) (RENZI[2015] 70HAO, Y5100619AM), DICP and QIBEBT (UN201804), Dalian National Laboratory For Clean Energy (DNL), CAS, and Research Innovation Fund (QIBEBT SZ201801).

\section{References}

[1] I. Roger, M. A. Shipman, M. D. Symes, Nat. Rev. Chem., 2017, 1, 


\section{Graphical Abstract}

Chin. J. Catal., 2019, 40: 1540-1547 doi: S1872-2067(19)63401-7

Iron-induced 3D nanoporous iron-cobalt oxyhydroxide on carbon cloth as a highly efficient electrode for oxygen evolution reaction

Guodong Chen, Jian Du, Xilong Wang, Xiaoyue Shi, Zonghua Wang *, Han-Pu Liang *

Qingdao University; Qingdao Institute of Bioenergy and Bioprocess Technology, Chinese Academy of Sciences; University of Chinese Academy of Sciences

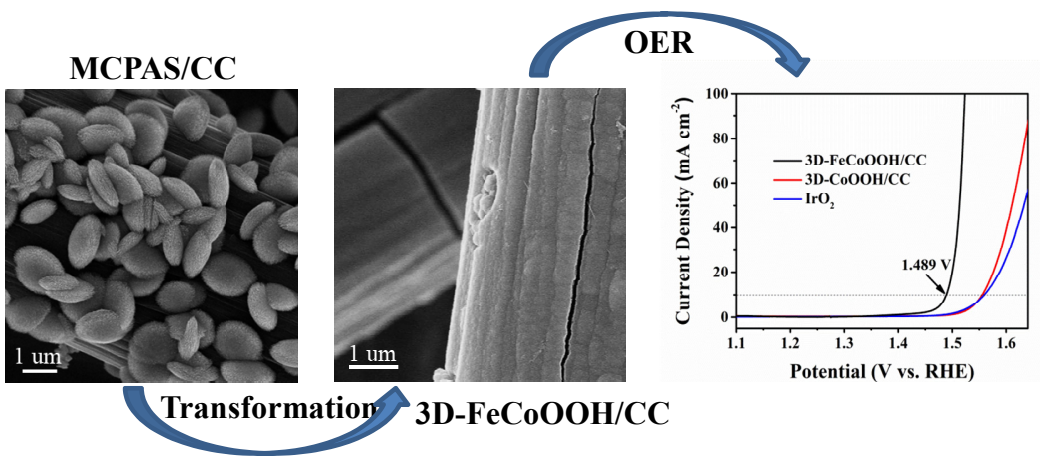

"Micro go chess piece" arrays on carbon cloth (MCPAs/CC) were transformed into a three-dimensional nanoporous iron-cobalt oxyhydroxide conformal coating on carbon cloth (3D-FeCoOOH/CC) via electrochemical oxidation. Superior OER performance was exhibited by $3 \mathrm{D}-\mathrm{FeCoOOH} / \mathrm{CC}$, thereby outperforming $\mathrm{IrO}_{2}$.

0003.

[2] Y. C. Pi, Q. Shao, P. T. Wang, F. Lv, S. J. Guo, J. Guo, X. Q. Huang, Angew. Chem. Int. Ed., 2017, 56, 4502-4506.

[3] Y. Q. Zhang, B. Ouyang, J. Xu, G. C. Jia, S. Chen, R. S. Rawat, H. J. Fan, Angew. Chem. Int. Ed., 2016, 55, 8670-8674.

[4] Y. G. Li, P. Hasin, Y. Y. Wu, Adv. Mater., 2010, 22, 1926-1929.

[5] B. Zhang, X. L. Zheng, O. Voznyy, R. Comin, M. Bajdich, M. Garcia-Melchor, L. L. Han, J. X. Xu, M. Liu, L. R. Zheng, F. P. Garcia de Arquer, C. T. Dinh, F. J. Fan, M. J. Yuan, E. Yassitepe, N. Chen, T. Regier, P. F. Liu, Y. H. Li, P. De Luna, A. Janmohamed, H. L. Xin, H. G. Yang, A. Vojvodic, E. H. Sargent, Science, 2016, 352-337.

[6] Z. Y. Chen, Y. Song, J. Y. Cai, X. S. Zheng, D. D. Han, Y. S. Wu, Y. P. Zang, S. W. Niu, Y. Liu, J. F. Zhu, X. J. Liu, G. M. Wang, Angew. Chem. Int. Ed., 2018, 57, 5076-5080.

[7] E. L. Hu, Y. F. Feng, J. W. Nai, D. Zhao, Y. Hu, X. W. Lou, Energy Environ. Sci., 2018, 11, 872-880.

[8] Y. B. Huang, M. Zhang, P. Liu, F. L. Chen, L. S. Wang, Chin. J. Catal., 2016, 37, 1249-1256.

[9] J. Rosen, G. S. Hutchings, F. Jiao, J. Am. Chem. Soc., 2013, 135, 4516-4521.

[10] L. Trotochaud, S. L. Young, J. K. Ranney, S. W. Boettcher, J. Am. Chem. Soc., 2014, 136, 6744-6753.

[11] M. S. Burke, M. G. Kast, L. Trotochaud, A. M. Smith, S. W. Boettcher, J. Am. Chem. Soc., 2015, 137, 3638-3648.

[12] F. Yu, H. Q. Zhou, Z. Zhu, J. Y. Sun, R. He, J. M. Bao, S. Chen, Z. F. Ren, ACS Catal., 2017, 7, 2052-2507.

[13] A. Mendoza-Garcia, H. Y. Zhu, Y. S. Yu, Q. Li, L. Zhou, D. Su, M. J. Kramer, S. H. Sun, Angew. Chem. Int. Ed., 2015, 54, 9642-9645.

[14] X. X. Ma, Y. Q. Chang, Z. Zhang, J. L. Tang, J. Mater. Chem. A, 2018, 6, 2100-2106.

[15] J. H. Yu, G. Z. Cheng, W. Luo, J. Mater. Chem. A, 2017, 5, 15838-15844.

[16] Q. Zhao, D. Z. Zhong, L. Liu, D. D. Li, G. Y. Hao, J. P. Li, J. Mater. Chem. A, 2017, 5, 14639-14645.
[17] J. Suntivich, K. J. May, H. A. Gasteiger, J. B. Goodenough, Y. Shao-Horn, Science, 2011, 334, 1383-1385.

[18] L. Z. Zhuang, L. Ge, Y. S. Yang, M. R. Li, Y. Jia, X. D. Yao, Z. H. Zhu, Adv. Mater., 2017, 29, 1606793.

[19] X. T. Han, C. Yu, S. Zhou, C. T. Zhao, H. W. Huang, J. Yang, Z. B. Liu, J. J. Zhao, J. S. Qiu, Adv. Energy Mater., 2017, 7, 1602148.

[20] Z. C. Wang, H. L. Liu, R. X. Ge, X. Ren, J. Ren, D. J. Yang, L. X. Zhang, X. P. Sun, ACS Catal., 2018, 8, 2236-2241.

[21] Y. Li, F.-M. Li, X.-Y. Meng, S.-N. Li, J.-H. Zeng, Y. Chen, ACS Catal., 2018, 8, 1913-1920.

[22] F. Song, X.L. Hu, J. Am. Chem. Soc., 2014, 136, 16481-16484.

[23] S.-H. Ye, Z.-X. Shi, J.-X. Feng, Y.-X. Tong, G.-R. Li, Angew. Chem. Int. Ed., 2018, 57, 2672-2676.

[24] F. Song, K. Schenk, X. L. Hu, Energy Environ. Sci., 2016, 9, 473-477.

[25] J. W. Li, Q. N. Zhuang, P. M. Xu, D. W. Zhang, L. C. Wei, D. S. Yuan, Chin. J. Catal., 2018, 39, 1403-1410.

[26] J. F. Xie, X. D. Zhang, H. Zhang, J. J. Zhang, S. Li, R. X. Wang, B. C. Pan, Y. Xie, Adv. Mater., 2017, 29, 1604765.

[27] H. Xu, Z.-X. Shi, Y.-X. Tong, G.-R. Li, Adv. Mater., 2018, 30, 1705442.

[28] J. Q. Tian, Q. Liu, A. M. Asiri, X. P. Sun, J. Am. Chem. Soc., 2014, 136, 7587-7590.

[29] C. C. McCrory, S. Jung, J. C. Peters, T. F. Jaramillo, J. Am. Chem. Soc., 2013, 135, 16977-16987.

[30] M. Thommes, K. Kaneko, A. V. Neimark, J. P. Olivier, F. Rodriguez-Reinoso, J. Rouquerol, K. S. W. Sing, Pure Appl. Chem., 2015, 87, 1051-1069.

[31] K. Fan, Y. F. Ji, H. Y. Zou, J. F. Zhang, B. C. Zhu, H. Chen, Q. Daniel, Y. Luo, J. G. Yu, L. C. Sun, Angew. Chem. Int. Ed., 2017, 56, 3289-3293.

[32] F. M. Tang, W. R. Cheng, H. Su, X. Zhao, Q. H. Liu, Angew. Chem. Int. Ed., 2017, 56, 3289-3293.

[33] J. Yang, H. W. Liu, W. N. Martens, R. L. Frost, J. Phys. Chem. C, 2010, 114, 111-119.

[34] Z. Chen, C. X. Kronawitter, Y.-W. Yeh, X.F. Yang, P. Zhao, N. Yao, B. E. Koel, J. Mater. Chem., 2017, 5, 842-850. 
[35] J. Du, C. Li, X. L. Wang, T. G. J. Jones, H.-P, Liang, Electrochim. Acta, 2019, 303, $231-238$.

[36] J. H. Huang, J. T. Chen, T. Yao, J. F. He, S. Jiang, Z. H. Sun, Q. H. Liu, W. R. Cheng, F. C. Hu, Y. Jiang, Z. Y. Pan, S. Q. Wei, Angew. Chem. Int. Ed., 2015, 54, 8722-8727.

[37] R. R. Zhang, Z. T. Sun, C. C. Zong, Z. Y. Lin, H. Huang, K. Yang, J. Chen, S. Liu, M. X. Huang, Y. Yang, W. H. Zhang, Q. W. Chen, Nano Energy, 2018, $57,753-760$.
[38] M. G. Walter, E. L. Warren, J. R. McKone, S. W. Boettcher, Q. X. Mi, E. A. Santori, N. S. Lewis, Chem. Rev., 2010, 110, 6446-6473.

[39] T. R. Zhan, S. S. Lu, X. L. Liu, H. N. Teng, W. G. Hou, Electrochim. Acta, 2018, 265, 681-689.

[40] M. W. Xie, L. Yang, Y. Y. Ji, Z. Q. Wang, X. Ren, Z. A. Liu, A. M. Asiri, X. L. Xiong, X. P. Sun, Nanoscale, 2017, 9, 16612-16615.

[41] H. Y. Li, S. M Chen, Y. Zhang, Q. H. Zhang, X. F. Jia, Q. Zhang, L. Gu, X. M. Sun, L. Song, X. Wang, Nat. Commun., 2018, 9, 2452.

\title{
铁诱导生长在碳布上三维纳米多孔铁钴羟基氧化物作为高效电催化析氧反应电极
}

\author{
陈国栋 ${ }^{\mathrm{a}, \dagger}$ ，杜 健 ${ }^{\mathrm{b}, \dagger}$ ，王西龙 ${ }^{\mathrm{b}}$, 时晓玥 ${ }^{\mathrm{b}}$, 王宗花 ${ }^{\mathrm{a},}{ }^{*}$, 梁汉璞 $\mathrm{b}, \mathrm{c}$, , \\ 青岛大学化学化工学院, 中日碳纳米材料合作研究中心, 山东青岛 266071 \\ $\mathrm{b}$ 中国科学院青岛生物能源与过程研究所, 山东青岛 266101 \\ ${ }^{\mathrm{c}}$ 中国科学院大学材料科学与光电工程中心, 北京 100049
}

\begin{abstract}
摘要: 开发高效、廉价的电极材料应用于电催化氧析出反应(OER)在水分解技术中起着至关重要的作用. 提高催化剂催化 活性的策略主要有两种,一是通过调整催化剂形貌和结构来增加催化活性位点数量, 二是通过掺入其它组分来增强催化活 性位点的反应活性. 本工作结合这两种策略, 通过原位电氧化方法成功合成了生长在碳布上具有独特三维结构的纳米多孔 铁钴羟基氧化物 (3D-FeCoOOH/CC), 合成的电极材料直接用作电催化析氧反应的工作电极. 以生长在碳布上的 “微型棋子” 阵列 $\left(\mathrm{MCPAs} / \mathrm{CC}\right.$ ) 作为前驱体, 先后通过在 $\left(\mathrm{NH}_{4}\right)_{2} \mathrm{Fe}\left(\mathrm{SO}_{4}\right)_{2}$ 溶液中进行 $\mathrm{Fe}$ 掺杂工艺和在碱性介质中原位电化学氧化制备了 $3 \mathrm{D}-\mathrm{FeCoOOH} / \mathrm{CC}$. 微观表征表明, $\mathrm{MCPAs} / \mathrm{CC}$ 上的 “微型棋子” 阵列完全转化为一层薄形涂层包覆在碳布纤维上. 电化学测 试结果表明, 合成的 $3 \mathrm{D}-\mathrm{FeCoOOH} / \mathrm{CC}$ 在 $1.0 \mathrm{~mol} \mathrm{~L}^{-1} \mathrm{KOH}$ 溶液中表现出优异的OER催化活性, 在电流密度为 $10 \mathrm{~mA} \mathrm{~cm}{ }^{-2}$ 时所 需的过电势仅为 $259 \mathrm{mV}$, 塔菲尔斜率为 $34.9 \mathrm{mV} \mathrm{dec}^{-1}$, 并且具有优异的稳定性. 详细的表征表明, 电化学表面积的增加、电导 率的增高、 $\mathrm{FeCo}$ 双金属组成和独特的3D多孔结构共同使得 $3 \mathrm{D}-\mathrm{FeCoOOH} / \mathrm{CC}$ 的催化OER活性增强. 此外, 本实验所应用的 合成策略可以扩展到制备一系列其他过渡元素掺杂的 $\mathrm{Co}$ 基电极材料.

利用选区电子衍射、红外光谱和XPS等技术证明了双金属羟基氧化物的合成. 从扫描电子显微镜图和透射电子显微镜 图可以看出, 本实验所合成的 $3 \mathrm{D}-\mathrm{FeCoOOH} / \mathrm{CC}$ 具有多孔结构, 相应的元素分布图表明 $\mathrm{Fe}$ 和 Co元素在催化剂中均匀分布. $\mathrm{N}_{2}$ 吸脱附测试进一步证明了多孔结构的生成. XPS测试结果表明, 前驱体中Co元素为 +2 价, $3 \mathrm{D}-\mathrm{CoOOH} / \mathrm{CC}$ 中的 Co元素为 +3 价, Co $2 p$ 电子结合能分别为 780.5 和 $795.7 \mathrm{eV}$, 当将 $\mathrm{Fe}$ 引入其中时, $3 \mathrm{D}-\mathrm{FeCoOOH} / \mathrm{CC}$ 中的 $\mathrm{Co}$ 元素也为 +3 价, 但 $\mathrm{Co} 2 p$ 电子结合 能变为780.9和796.1 eV. 相比于 $3 \mathrm{D}-\mathrm{CoOOH} / \mathrm{CC}, 3 \mathrm{D}-\mathrm{FeCoOOH} / \mathrm{CC}$ 中 $\mathrm{Co}$ 元素的电子结合能增加了 $0.4 \mathrm{eV}$, 这表明 $\mathrm{Fe}$ 的引入调 节了 Co 原子的电子结构, 并且 $\mathrm{Fe}$ 原子和 Co 原子之间存在强烈的相互作用. $3 \mathrm{D}-\mathrm{FeCoOOH} / \mathrm{CC}$ 在 $785 \mathrm{eV}$ 处增强的 Co的伴随 峰表明Co原子的简并轨道被破坏引起Co $3 d$ 电子群重排, 而Co $3 d$ 电子群的重排导致Co原子电子密度增加, 有利于催化活性 的增强. 此外 $\mathrm{Fe}$ 元素的加入可以调节 $\mathrm{OH}$ 在催化剂上的吸附, 从而增强催化活性.

$3 \mathrm{D}-\mathrm{FeCoOOH} / \mathrm{CC}$ 表现出优异的电催化析氧性能, 可以归因于以下几方面: 首先, $\mathrm{Fe}$ 元素掺入提高电极材料的电化学活 性面积(ECSA)、电导率和质量传递; 其次, $\mathrm{Co}$ 与掺杂 $\mathrm{Fe}$ 之间的强烈相互作用调节了电子密度和 $\mathrm{OH}$ 在催化剂表面吸附; 第三, $3 \mathrm{D}-\mathrm{FeCoOOH} / \mathrm{CC}$ 独特的 $3 \mathrm{D}$ 多孔结构具有较大的表面积, 有利于催化活性位点的暴露、电解质与催化剂的接触和产生氧气 的释放; 第四, 独特的 $3 \mathrm{D}$ 多孔电极材料具有良好的结构稳定性, 从而使 $3 \mathrm{D}-\mathrm{FeCoOOH} / \mathrm{CC}$ 具有更好的稳定性. 得益于上述优 势, 本实验所合成的3D-FeCoOOH/CC电极表现出优异的电催化析氧性能.
\end{abstract}

关键词: 3D纳米多孔铁钴羟基氧化物; 微型棋子阵列; 电极材料; 电氧化; 氧析出反应

收稿日期: 2019-05-22. 接受日期: 2019-06-23. 出版日期: 2019-10-05.

*通讯联系人. 电话: (0532)85950873; 电子信箱: wangzonghua@qdu.edu.cn

\#通讯联系人. 电话: (0532)80662638; 电子信箱: lianghp@qibebt.ac.cn

“共同第一作者.

基金来源: 山东泰山学者计划(ts201511027); 山东省自然科学基金(2018GGX102030); 中国科学院百人计划(Y5100619AM); 中 国科学院大连化学物理研究所和青岛生物能源与过程研究所融合基金(UN201804); 青岛生物能源与过程研究所研究创新基金 (QIBEBT SZ201801).

本文的电子版全文由Elsevier出版社在ScienceDirect上出版(http://www.sciencedirect.com/science/journal/18722067). 